\title{
HIGH DIVISION OF BRACHIAL ARTERY- A CASE REPORT
}

\author{
K. Smitha Elizabeth
}

1. Assistant Professor. Department of Anatomy, Shri B M Patil medical College \& Research Centre, Bijapur.

\section{CORRESPONDING AUTHOR}

K. Smitha Elizabeth,

Assistant Professor, Department of Anatomy,

Venkateshwara Medical College \& Research Centre,

Ariyur, Pondicherry, 605102.

E-mail: smithakore@yahoo.in

Ph: 00919698812162.

\begin{abstract}
Variations in the arteries of the upper limb are commonly seen. Most of these variations are seen as variant division of axillary artery and as high origin of radial or ulnar artery. In the present case a higher division of brachial artery was seen, with the artery dividing in the arm just distal to teres major muscle into its terminal branches, the radial artery laterally and ulnar artery medially, the artery had passed superficial to the median nerve before its division. The other branches, profunda brachii and superior ulnar collateral arteries arose from brachial artery whereas the inferior ulnar collateral artery arose from the ulnar artery. Knowledge of such variations is important in view of their clinical significance and they need to be considered prior to surgical procedures.
\end{abstract}

KEYWORDS: Variation, brachial artery, ulnar artery, radial artery

INTRODUCTION: Brachial artery is the main source of arterial supply to the arm, it begins as a continuation of axillary artery at the distal border of teres major muscle, and ends at the level of neck of radius by dividing into its terminal branches radial and ulnar arteries. The median nerve crosses in front of the artery from lateral to medial side, at the middle of the arm.

Apart from the terminal branches, the branches of the brachial artery in the arm are profunda brachii, superior ulnar collateral artery, inferior ulnar collateral artery, muscular branches to the surrounding muscles and a nutrient branch to the humerus [1].

Variations in the divisions of the brachial artery have been reported, the brachial artery divides more proximally than usual into radial, ulnar and common interosseous artery. The anomalous brachial vessels sometimes result from high division of brachial artery with two arteries proceeding to the cubital fossa instead of the usual one [2, 3].

A similar finding is encountered in our case where the brachial artery divided into terminal divisions in the arm, instead of dividing in the cubital fossa, such a division is clinically significant.

MATERIAL AND METHODS: The present study was done on the embalmed cadavers utilized for dissection by the undergraduate students in the department of Anatomy. During the dissection of the upper limb skin, superficial fascia, deep fascia and muscles were separated using a scalpel and forceps, the origin and course of the vessels and nerves were studied on both the sides. A variation was seen on the right side of the upper limb of an adult male cadaver, which was seen as a high division of brachial artery. The brachial artery was carefully followed noting its commencement, course, termination and branches, the brachial artery was later colored and photographs were taken before and after coloring. 
OBSERVATION: A variation was seen on the right side of the upper limb of an adult male cadaver, where the brachial artery divided into its terminal branches in the middle third of the arm, about $5 \mathrm{~cm}$ distal to the lower border of teres major [fig 1].

The brachial artery passed superficial to the median nerve, after division the lateral branch crossed the median nerve, from medial to lateral side and continued as the radial artery in the fore arm. The medial branch passed medial to the median nerve and continued as the ulnar artery. Both the ulnar and radial arteries passed superficial to the muscles in the arm [fig2].

The brachial artery gave rise to its branches the profunda brachii artery in its proximal part, muscular branches to the surrounding muscles. The superior ulnar collateral artery arose from the distal part of the brachial artery whereas the inferior ulnar collateral branch arose from the proximal part of the ulnar artery in the arm instead of arising from the brachial artery [fig3]. The further course of the ulnar and radial artery was normal in the forearm and hand. No such variation was seen on the left side.

DISCUSSION: Variations in the arterial system of the upper limb have been reported, McCormack et al published a study of 750 dissected upper extremities, where the percentage of major arterial pattern variation was $18.53 \%$ of total [4].

Major variations in the division of brachial artery are seen in about $25 \%$ of the subjects; high origin of radial and ulnar artery was seen as the highest percentage of variations of brachial artery [5].

In a study involving 56 cadavers, only one specimen with a bilateral variation (1.78\%), was seen, indicating the rare existence of this variation bilaterally [6]

Hollinshead mentions that the superficial arteries in the arm are relatively common, and reported in $30 \%$ of bodies, they are usually unilateral but sometimes bilateral and occur in about $18 \%$ of limbs. Superficial radial arteries constitute about $75 \%$ of all superficial arteries of the arm [3].

Guha et al. observed high up division of brachial artery into radial and ulnar arteries in the middle of the arm associated with variant median nerve and absent musculocutaneous nerve [7]

A study on 384 limbs described 7 arterial variations in the major arteries of the upper limb, $11 \%$ were seen to be superficial brachial artery, so called as the brachial artery coursed superficial to the median nerve [8], in the present case also such a superficial course of brachial artery was seen.

Satyanarayana et al also mentioned about the embryological basis and clinical significance of the high division of brachial artery but in his case the median nerve passed superficial to the artery [9].

Arey is of the view that the anomalous vessels may be due (i) the choice of unusual paths in the primitive vascular plexus (ii) persistence of vessels normally obliterated (iii) the disappearance of vessels normally retained (iv) incomplete development (v) fusions and absorption of the parts usually distinct [10].

The present variation can be explained on the basis of embryological development of vascular plexus of the limb buds. The axis artery of upper limb-bud is derived from the lateral branch of seventh intersegmental artery. Proximal part of main trunk forms the axillary artery continuing as brachial artery and its distal part persists as the anterior interosseous artery. The radial and ulnar arteries are last arteries to appear in the forearm at first, the radial artery 
arises more proximally than the ulnar artery from the main trunk and crosses in front of the median nerve. Later, the radial artery establishes a new connection with the main trunk at or near the level of origin of the ulnar artery. The upper part of the original stem usually disappears to a large extent. Thus radial and ulnar arteries arise at same level [11].

In this case, the proximal origin of radial artery may have failed to disappear, and the radial artery did not establish a new connection with main trunk near the origin of ulnar artery. Thus the radial artery originated at a higher level and main artery of the limb continued as the ulnar artery.

Variations in branches of the brachial artery are also reported, where the branches arose from either axillary artery or from a common trunk [12].

An accurate knowledge of the relations and course of such large arterial conduits and particularly of its variational pattern is of considerable practical importance in the conduct of reoperative surgeries of the upper limb [4]. Serious secondary haemorrhage may occur when the surgeon has identified only those vessels which are usually present in the region. [13].

Superficial aberrant arteries may be more vulnerable to trauma, and thus to haemorrhage, leading to intra arterial injections, wrong-interpretations of incomplete angiographic images or severe disturbances of hand irrigation during surgical procedures of the arm [14].

A case where the brachial artery bifurcation variant posed a potential hidden hazard which was encountered in percutaneous brachial artery catheterization techniques has been reported [15].

Such variations are important even for clinicians in day to day practice in relation to is pulsation being measured for blood pressure.

CONCLUSION: Morphological variations in the division of brachial artery bear considerable significance from the surgical point of view. Advances in medicine have increased brachial artery utilization for diagnostic and interventional radiology

Hence knowledge of these variations is of practical importance for surgeons and radiologist, and is to be considered before any clinical procedure being initiated.

\section{REFERENCES}

1. Standstring S. Gray's Anatomy: the anatomical bases of clinical practice. 39th ed. Edinburg : Churchill Livingstone ; 2005.p. 856.

2. Williams PL, Bannister LH, Berry MM, Collins P, Dyson M, Dussek JE, Ferguson MW, eds. Gray's Anatomy. 38th Ed., London, Churchill Livingstone. 1999; 319, 1539.

3. Hollinshead WH, Rosse C. Textbook of Anatomy. 4th ed. New York : Harper and Row ; 1962.p.214.

4. Mac Cormack L J, Cauldevell EW, Anson BJ, Brachial and anterbrachial arterial patterns a study of 750 extremities. Surg Gynecol Obstet $1953 ; 96: 43-54$.

5. Bergman RA, Thompson SA, Afifi AK, Saadeh FA. Compendium of human anatomic variation. Baltimore: Urban \& Schwarzenberg; 1988.

6. Rossi Junior, WC, Esteves, A., Simões, JS. et al. J. Morphol. Sci., 2011; 28( 3) : 204-207.

7. Guha R, Palit S. A rare variation of anomalous median nerve with absent musculocutaneous nerve and high up division of brachial artery. J Interacad. 2005; 9: 398-403. 
8. Rodriguez M, Vazquez T, Nearn L, Ferreira B, Parkin I, Sanudo JR. Variations of the arterial pattern in the upper limb revisited: A morphological and statistical study, with a review of the literature. J Anat 2001; 199: 547-566.

9. Satyanarayana, Sunitha P, munvar miya shaik, satya vathi dev P. IJAV. 2010; 3: 56-58.

10. Arey LB. Developmental anatomy. In: Development of the arteries. 6th ed. Philadelphia:W B Saunders ; 1957.p.375-77.

11. Baral P, Vijayabhaskar P, Roy S, Kumar S, Ghimire S, Shrestha U. KUMJ.2009; 7 (3): 293-297.

12. Patnaik V.V.G, Kalsey G, Singla Rajan K. J Anat. Soc. India. 2002; 51(2):176-186.

13. Cherukupalli C, Dwivedi A, Dayal R. High bifurcation of brachial artery with acute arterial insufficiency: a case report. Vasc Endovascular Surg. 2007; 41:572-4.

14. Deligonul U, Gabliani G, Kern MJ, Vandormael M. Percutaneous brachial catheterization: the hidden hazard of high brachial artery bifurcation. Cathet Cardiovasc Diagn 1988; 14(1): 44-5.

15. Ivan James PrIthIshkumar, madhavI Chathu. JCDR. 2011; 5(4): 862-864.

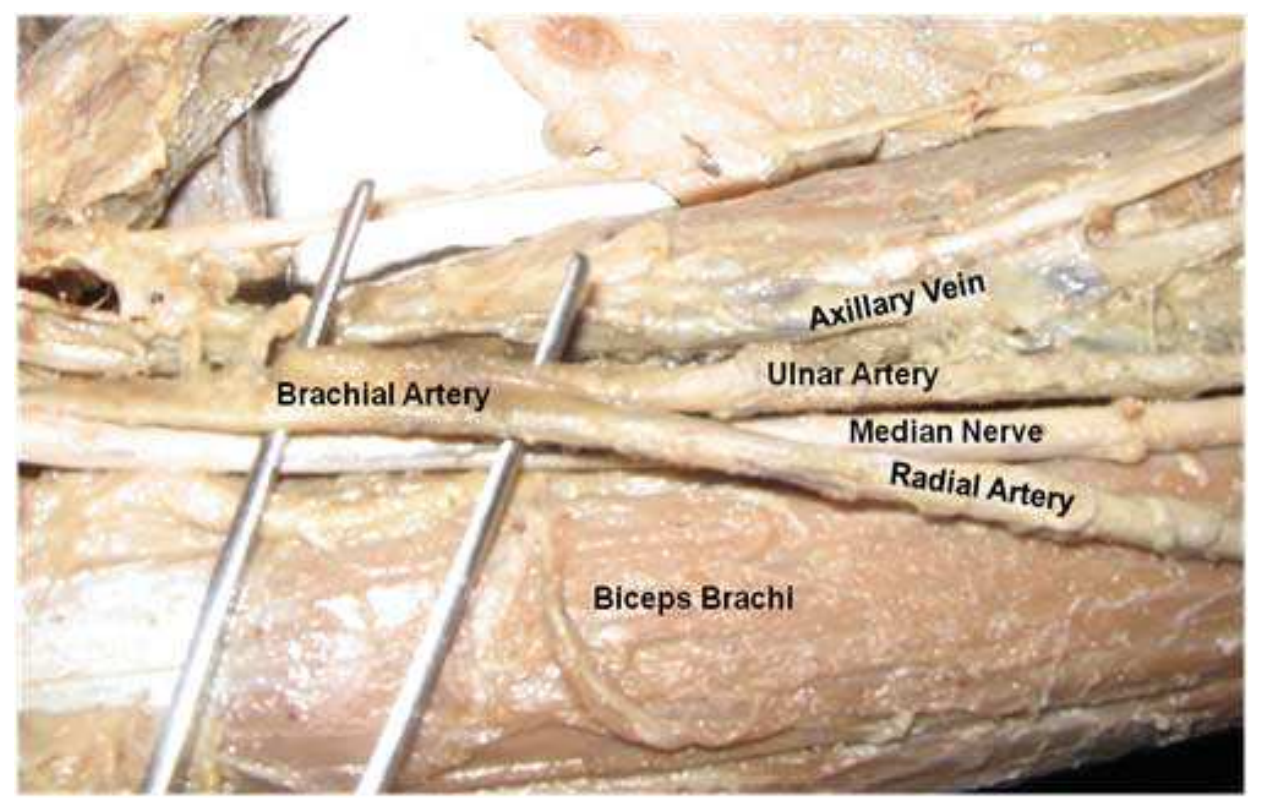

Fig 1: Right upper limb showing high division of brachial artery into radial and ulnar artery in the arm. 


\section{CASE REPORT}

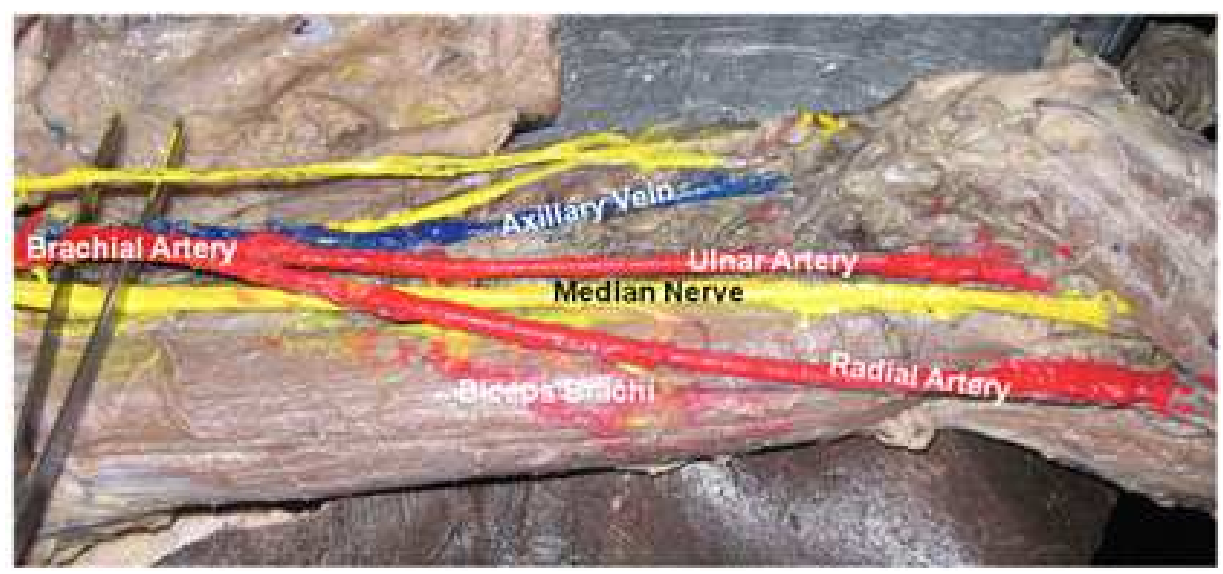

Fig 2: Right upper limb showing high division of brachial artery into radial and ulnar artery in the arm.

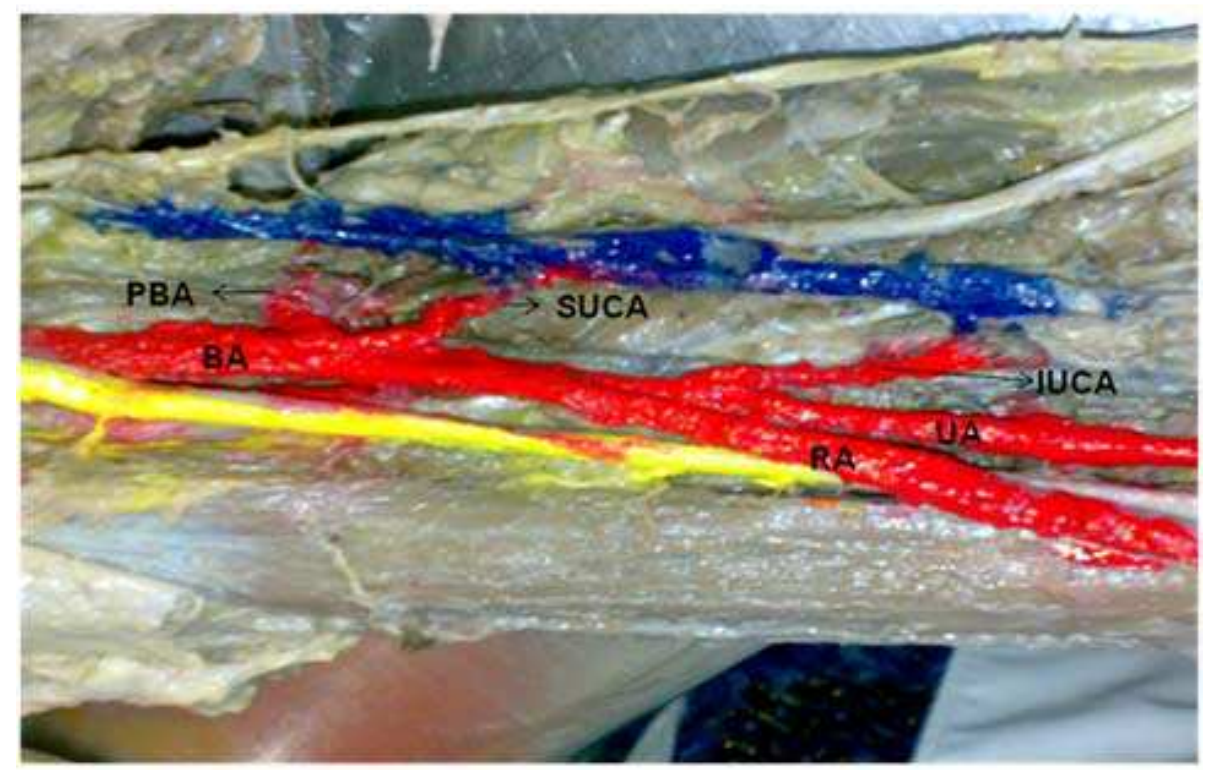

Fig3: Right upper limb showing the branches of brachial artery (BA), profunda brachii artery (PBA) and superior ulnar collateral artery (SUCA) arising from brachial artery before division. Inferior ulnar collateral artery (IUCA) arising from ulnar artery (UA), no branches arose from radial artery (RA) in the arm 